\title{
Multi-Modal Oral Implantology. The Screw-Blade Single-Implant for the Replacement of the Upper Molar: A Case Report
}

\author{
Luca Dal Carlo, Zeno Dal Carlo, Marco E. Pasqualini, Franco Rossi, Mike Shulman
}

\section{ABSTRACT}

Intense forces are naturally downloading on molar roots. Due to inflammation, the post-extraction sockets of the upper molars are often poor of bone on one side. A single implant supporting a prosthetic crown can easily go subject to displacing forces that reabsorbed and recently healed bone can hardly bear. By utilizing a couple of prosthetic roots, i.e.: one screw implant in the side in which bone is richer and one blade implant in the side in which the bony wall has gone subject to reabsorption, it is possible to build a better supported prosthetic crown. The clinical cases performed by the Authors confirm the validity of this implant architecture.

Aim of the work is to describe a post-extraction multi-modal implantological technique useful for replacing the roots of upper molars with poor bone support on one side.

Materials and methods: Combination of submerged screw implant and submerged blade implant or emergent screw implant and emergent blade implant welded intraorally.

Discussion: The combination of a palatal screw implant and a buccal blade implant, or vice versa, allowed to solve clinical cases and to make reliable prosthetic crowns.

Conclusions: The presence of variable residual anatomies in the molar area of the upper jaw recommends the use of morphologically different implant shapes, suitable for the construction of a biomechanically functional prosthetic abutment. Specifically in the presence of bone resorption, the combination of a screw implant and a blade implant allowed us to obtain a reliable abutment. Given the small number of cases performed, further research will confirm the positive results of this technique.

Keywords: Blade implant, post-extraction implant, wedge form implant.
Submitted : September 28, 2021

Published : December 23, 2021

ISSN: $2593-8339$

DOI: $10.24018 /$ ejmed.2021.3.6.1082

\section{Dal Carlo*}

Dr. Luca Dal Carlo Dental Office,

Venice, Italy.

(e-mail: lucadalcarlo@gmail.com)

Z. Dal Carlo

Dr. Luca Dal Carlo Dental Office,

Venice, Italy.

(e-mail: zenodalcarlo96@gmail.com)

M. E. Pasqualini

Dr. ME Pasqualini Dental Office,

Milan, Italy.

(e-mail:

dott.marcopasqualini@gmail.com)

F. Rossi

Dr. Franco Rossi Dental Office,

Varese, Italy.

(e-mail: francorossi020@gmail.com)

\section{Shulman}

Renaissance Dental Group, New

Jersey, United States.

(e-mail: mike@adiseminars.com)

*Corresponding Author

\section{INTRODUCTION}

The placement of a post-extraction implant to replace a compromised natural root is a therapy widely practiced by specialists, especially with screw implants. In the case of single-rooted teeth, the screw implant usually has a size compatible with the prosthetic crown, without any particular bending and displacement forces being generated. In the event that the tooth to be replaced is a molar, it is often necessary to provide the support of more than one implant, because a single large-caliber implant is not always compatible with the residual bone anatomy. In these cases, different solutions are described in the literature: two submerged screw implants [1], [2] two welded emergent screw implants [3], stabilized screw implants with welded thin cylindrical implants [4]. The different choices derive from the need or not for immediate loading or from that of protecting the implant from intraoral destabilizing forces, mostly related to the thrust of the tongue in swallowing [5] and to chewing trauma in the period necessary for osteointegration. In the upper molar, the outcome of periodontal pathologies to which the roots have been subjected can lead to asymmetrical resorption of residual bone, leading to the use of a palatal screw implant associated with a vestibular blade implant or vice versa [2]. The results, in the cases performed, were satisfactory. We therefore consider this option as an additional therapeutic choice, also in consideration of further verifications.

\section{Diagnostic And Therapeutic Questions}

Frequently, the post-extraction site of a compromised upper molar is very critical for implantology. Before proceeding to place an implant, you need to ask yourself a few questions.

1) How deep is the remaining bone tissue?

2) What is the nature of the inflammatory or erosive 
process that led to the extraction of the tooth?

3) Which degree of bone resorption has been caused by the periodontal desease?

4) What is the arrangement of the remaining alveoli after extraction?

5) What is the state of the residual soft tissues?

6) Is it advisable to insert an implant or more than one?

7) How far is the distance to the opposing teeth?

8) Do the opposing teeth follow the Spee and Wilson curves?

9) Will the prosthetic crown be at risk due to the stress of the dynamic movements of the inferior jaw?

10) What forces will the prosthetic crown be subjected to?

11) What material is the antagonist made of?

The requirements that the new dental-root prosthesis will have to comply with are numerous and absence of attention to one or more of them could lead to premature failure of the therapy. One of the aspects that help the treatment with implants of this anatomical site is constituted by the fact that the edentulous site does not present problems of aesthetic importance and therefore classical biphasic implantology techniques can be used, following the timeline protocols for the formation of a valid bone tissue.

\section{ANALYSIS OF THE QUESTIONS}

The depth of the bone tissue above the apex of the roots of the upper molar (question no. 1) is often deficient due to the presence of the maxillary sinus. Very frequently the roots of the upper molars even protrude into it.

The permanence of the bone tissue that enveloped the dental roots is strongly conditioned by the pathological processes that the tooth has undergone over the years (questions 2 and 3). Normally, the upper molar has three wellseparated roots. Following tooth extraction, it is usual to find a strong resorption of the bone surrounding the vestibular roots, while the palatine alveolus remains well preserved. On the contrary, a molar with fused roots easily leaves, as a residue, a well centered alveolus in the alveolar process, easily treatable with a wide-diameter screw implant (Fig. 1A and $1 \mathrm{~B})$.
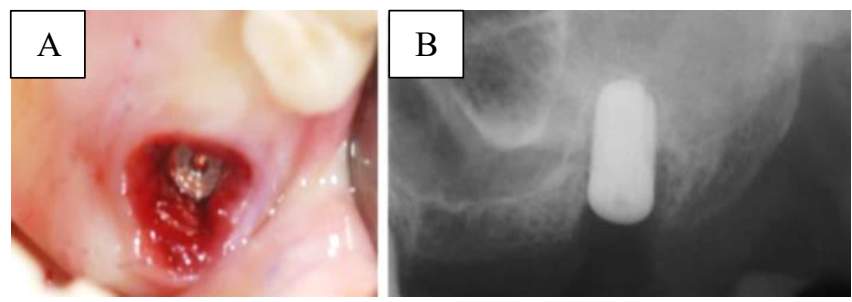

Fig. 1A. Wide-diameter submerged screw implant inserted after extraction of an upper molar with fused roots, which protrude into the maxillary sinus.

Fig. 1B. Intra-operative radiograph of a wide-diameter submerged screw implant inserted after extraction of an upper molar with fused roots.

Three diverging dental roots is the most frequent anatomical condition for superior $1^{\text {st }}$ molars. If the bone tissue of the alveoli is well preserved and the surgical extraction maneuver has been careful, it is possible to treat the three alveoli with two / three screw implants, obtaining a wellstabilized abutment in the bone tissue [6]. However, this is an infrequent occurrence (Fig. 2).

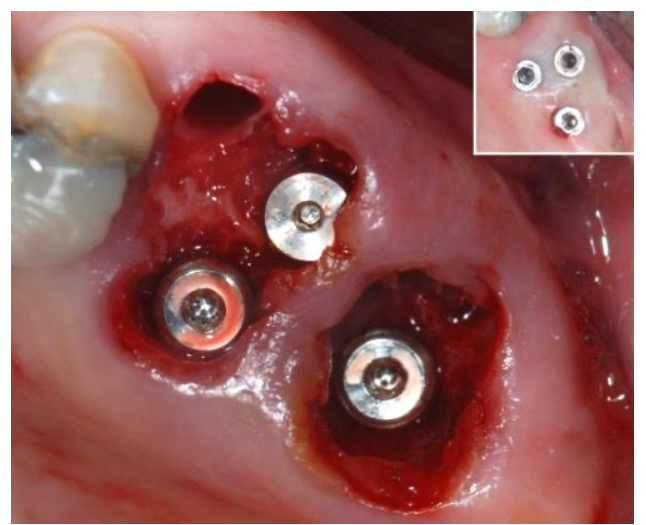

Fig. 2. Two submerged screw implants inserted immediately after extraction in the palatine and vestibule-distal alveoli of an upper 1st molar and one submerged screw implant inserted immediately after extraction in the center of the alveolus of 2 nd molar. The implants are enveloped in sufficient bone tissue. In the box upper right, situation after healing is displayed.

Very often, the bone tissue that surrounds the vestibular roots is strongly resorbed, counter-indicating the placement of vestibular screw implants, due to the lack of the external wall (questions 3-5).

The placement of a single implant in the palatal alveolus is often possible, but it involves the creation of a prosthetic crown in occlusal disharmony, therefore it could more easily deceive and/or produce stress on the implant-prosthetic component (peri-implantitis and / or fatigue fracture of the implant) [7]. In situations of occlusal inversion, this stress is further exacerbated (Fig. 3).

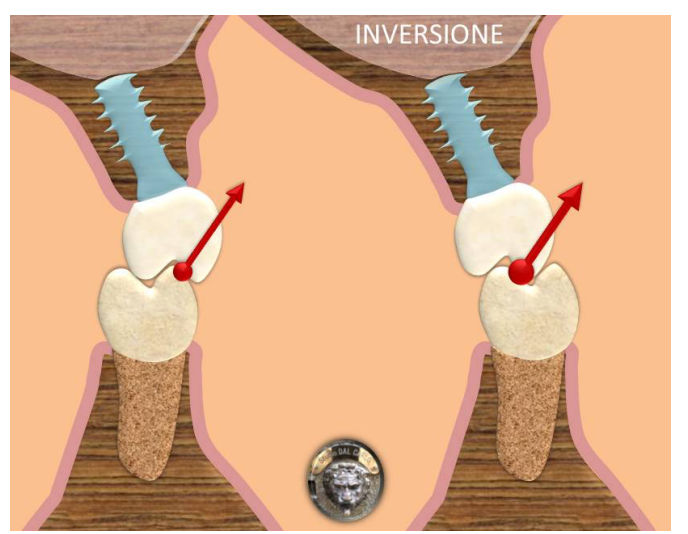

Fig. 3. If the prosthetic crown is supported by an implant positioned in the palatal alveolus of the extracted upper molar, the moment of force that is expressed in the functional movements tends to decree it, unscrew it or even break it. The presence of occlusal inversion aggravates the clinical situation, since the upper vestibular cusp is found to occlude with the center-fossa of the antagonist.

The non-axis positioning of the implant, for obvious biomechanical reasons, increases the risk of failure, especially in sites subject to intense load. In this regard, a simplified, easily applicable scheme was proposed by Fanali, with the Implant Prognostic Index (IPI). This index relates the horizontal distance between the implant axis and the antagonist, the vertical distance, and the inclination of the implant. From the three values, combined, we derive the index, which can indicate a low, medium, high, or very high risk. In the case of a misaligned implant inclined towards the palate, the risk index is high or very high [8].

It is therefore preferable to use two screw implants, as 
exemplified in Fig. 2. If the vestibular bone tissue underwent recession, the outermost screw implant would lack the space useful for the neoformation of bone tissue of adequate thickness, with the risk of dehiscence and consequent exposure of the coils (Fig. 4, left). The alternative is the insertion of a flat wedge-shaped implant, such as a Linkowtype blade (blade wedge-form implant) [9]-[13], in the residual bone tissue, which is more predictable than placing a screw implant without support of native bone tissue from the vestibular side. The blade implant, together with a screw positioned in the palatal alveolus, constitutes a balanced abutment from the bio-mechanical point of view, because the axial forces are transmitted to the cortical bone, thus eliminating bending momens of force (Fig 4, right).

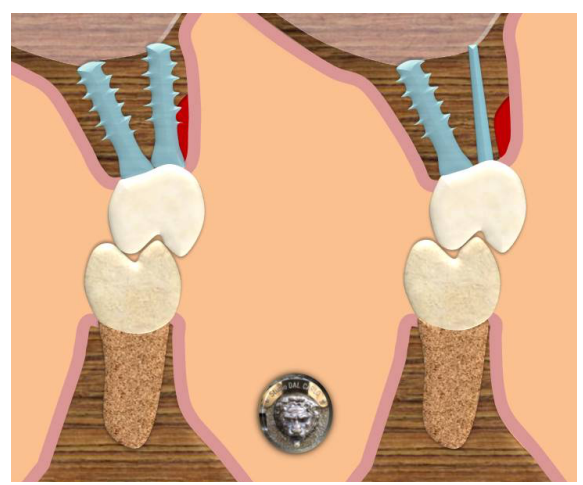

Fig. 4. The use of two screw implants to replace the roots of a molar is indicated if the two implants are wrapped by at least two millimeters of bone thickness. Often this thickness is not present, and the use of a flat implant is recommended.

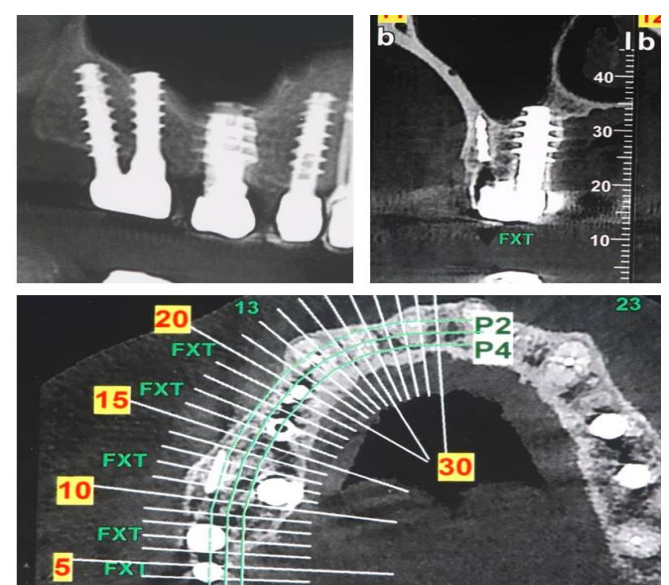

Fig. 5. CT 4 years after the mono-implant surgery consisting of a blade and a screw welded intraorally, inserted in area 1.6. The two implants are superimposed in the lateral view, while they are clearly distinguishable in the frontal and occlusal sections (TC sections 11-13). Also notice the single implant in zone 1.7-1.8 (2 screw implants 6 years after surgery) and the single implant in zone 1.5, replacing a single rooted tooth (screw implant 9 years after surgery).

In this way, a support area is created which collects the resultant of physiological, occlusal, and masticatory forces inside of it [2]. The flat shape of the blade withstands lateral forces (Fig. 5). This treatment strategy can also answer questions 4,7 and 10 .

\section{Clinical CASE}

Patient G.F., male, age 60, in good general health. The tooth element 2.6 was severely compromised (Fig. 6) and with the patient consent it was extracted (May 28, 2015). At the same time, having ascertained the presence of a palatal alveolus still endowed with bone support in all its circumference, it was decided to immediately place, after an adequate surgical toilet, a submerged screw implant. On the contrary, the severely periodontopathic vestibular roots had determined the loss of most of the vestibular bone support, so it was decided to insert a submerged blade implant (AZ Implant, Bologna Italy), in order to obtain a vestibular pillar leaving adequate space for neoformation on to the residual bone tissue (Fig. 7-9).

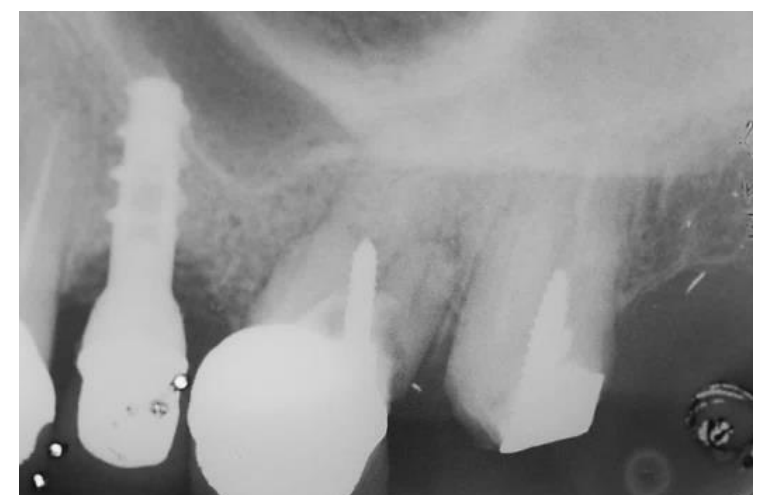

Fig. 6. Pre-operative X-ray (Dec. 16, 2014).

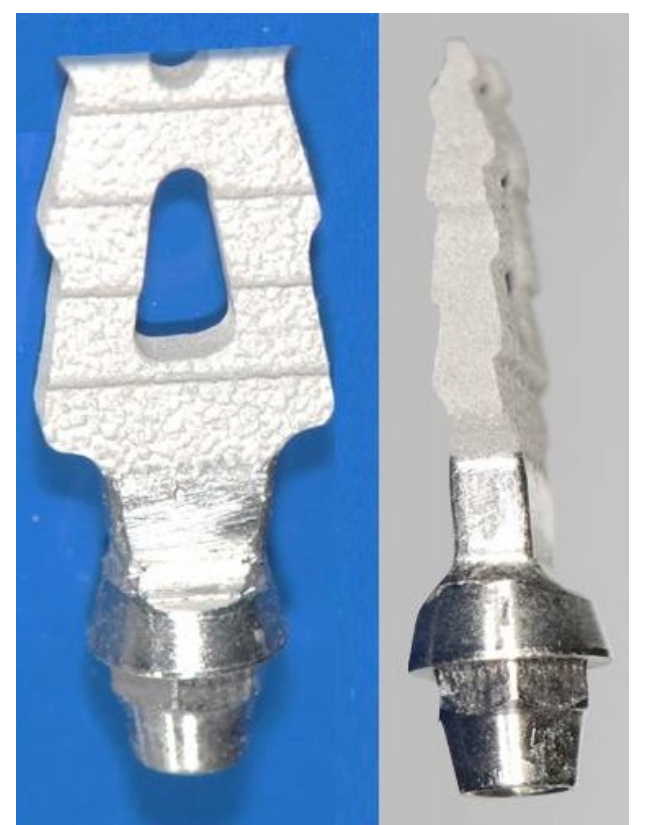

Fig. 7. Wedge-form submerged blade implant with hexagonal connection.

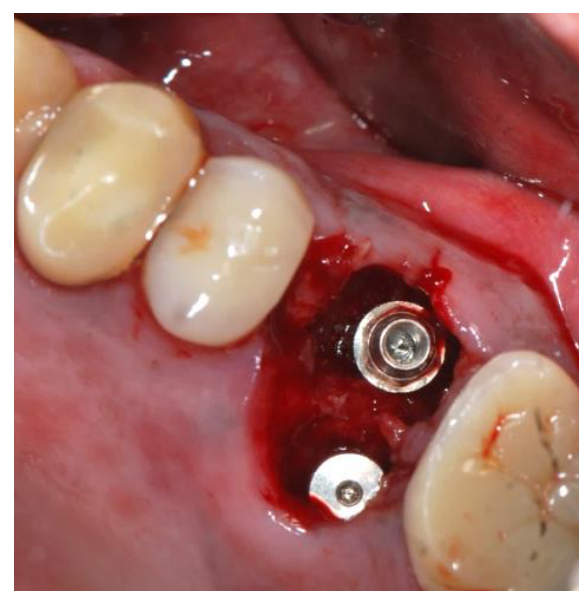

Fig. 8. Positioning, immediately after extraction, of a submerged blade implant in the buccal alveolus and a submerged screw implant in the palatal one. 


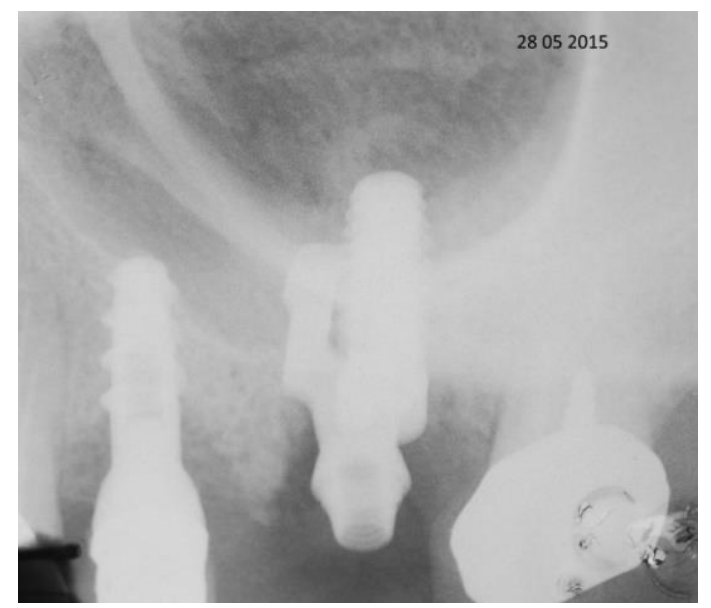

Fig. 9. RX. Positioning, immediately after extraction, of a submerged blade implant in the buccal alveolus and a submerged screw implant in the palatal one.

Six months later, the healing screws were removed (Fig. 10), the definitive abutments were fixed (Fig. 11) and the necessary steps were then carried out for the realization of the definitive prosthetic crown, fixed to two implant roots.

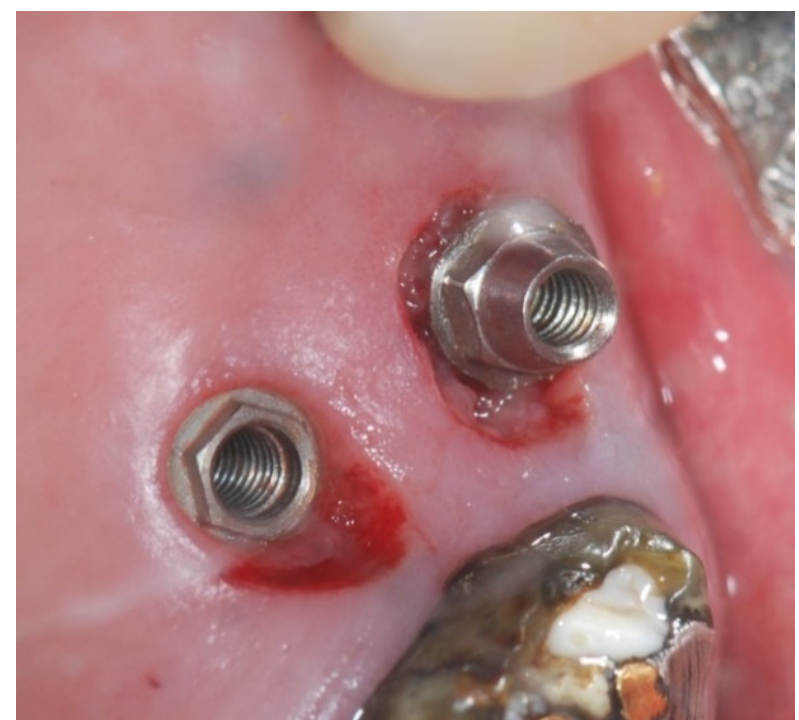

Fig. 10. The two implants in zone 2.6, palatal screw and buccal blade, after freeing the overlying gingival layer and removing the cover screws.

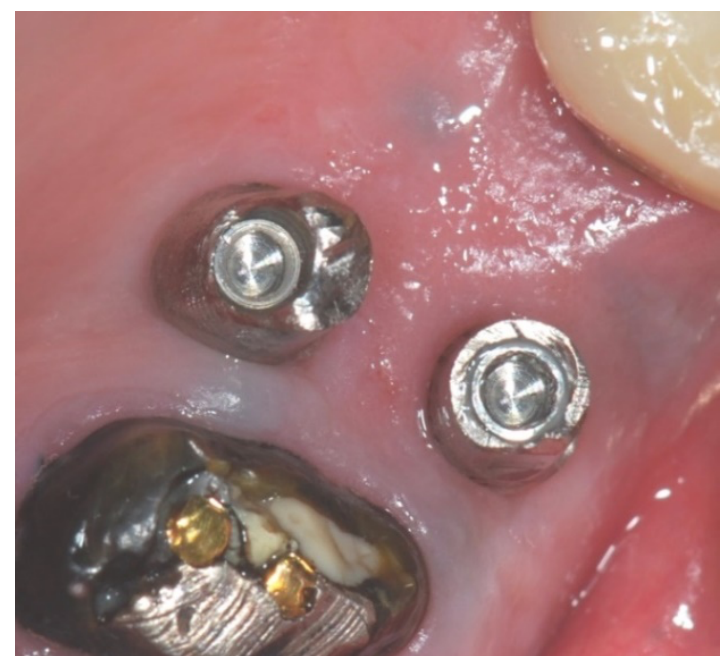

Fig. 11. The two implants, blade and screw, at the time of the final impressions.

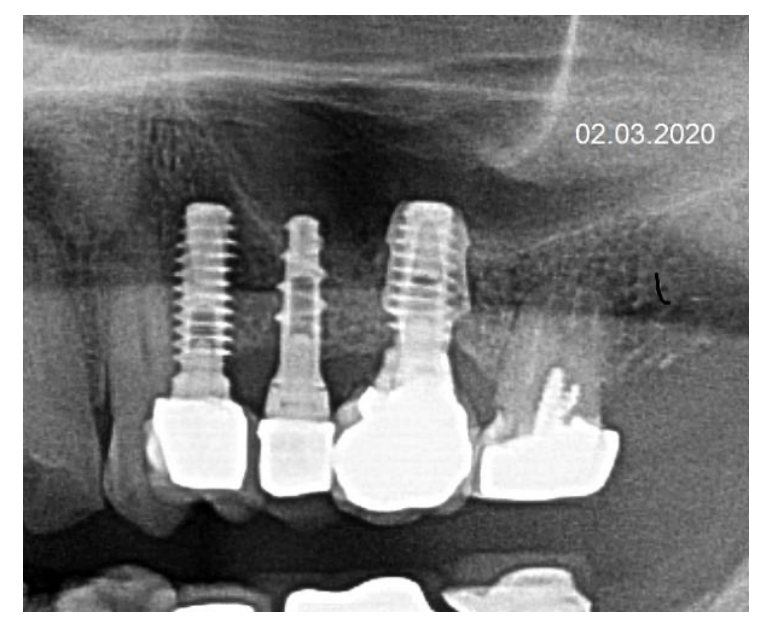

Fig. 12. Detail of the orthopantomography 5 years after the intervention (2020).

\section{DISCUSSION}

The possibility of using different implant shapes allows to broaden the horizons of treatment of complex clinical cases, avoiding procedures for modifying the residual bone anatomy, which are unpredictable especially when tissue regeneration or grafting are carried out in anatomical sites that have been subjected to inflammation for a long time. The need to create a structure with bio-mechanical equilibrium leads to the search for alloplastic posts that are able to withstand, without lateral deflections, the axial forces applied to the prosthetic crown. In the upper molar site, the combination of screw implant and blade implant allows to obtain a good clinical result even when the vestibular bone tissue is particularly reabsorbed. Our experience using single crowns supported by different shapes of implants confirms previous histological and research conclusions about identity of bone response and capability of withstanding masticatory forces by screw-type and wedge-type implants [14]-[33].

\section{COnClusions}

With this technique, the variety of single edentulous solutions is enriched by a method that, although used in a small number of cases, has so far given positive results. Further research will have to be carried out in order to include it in the suggested treatments of upper molar post-extraction alveoli with vestibular bone resorption.

\section{CONFLICTING INTERESTS}

Authors declare that they do not have any conflict of interest.

\section{FUNDING}

The authors received no financial support for the research, authorship and/or publication of this article.

\section{ACKNOWLEDGMENT}

The Authors are grateful to Prof. Leonard I. Linkow, Prof. Ugo Pasqualini and to all the Colleagues who gave tangible 
contribution to the development of blade implants.

\section{REFERENCES}

[1] Blatz MB, Strub JR, Gläser R, Gebhardt W. Use of wide-diameter and standard-diameter implants to replace single molars: two case presentations. Int J Prosthodont. 1998; 11(4): 356-63.

[2] Dal Carlo L, Dal Carlo Z, Belotti E: Elementi di selezione degli impianti endoossei. Edizioni Accademiche Italiane Schaltungsdienst Lange o.H.G., Berlin 2020. Italian.

[3] Pasqualini U, Pasqualini ME. Treatise of Implant Dentistry: The Italian Tribute to Modern Implantology. Carimate (IT): Ariesdue; 2009.

[4] Pasqualini M, Rossi F, Carlo LD, Comola G. Rehabilitations of a single element with one-piece implants with electrowelded needles: A different approach. Dent Res J (Isfahan). 2018; 15(6): 447-452.

[5] Dal Carlo L: Influenza della lingua sull'integrazione degli impianti endoossei. Doctor OS. 2003:14(5): 479-484.Italian.

[6] Dal Carlo L: L'ottimizzazione del tessuto peri-implantare marginale in implantologia sommersa. Or.Fix. 1998; 6: 12. Italian.

[7] Pasqualini ME: Le fratture da fatica dei metalli da impianto. Il Dentista Moderno, 1993; 2: 31. Italian.

[8] Fanali S, Dal Carlo L: La barra di contenzione elettrosaldata in implantologia orale: criteri per la rimozione o il mantenimento. Doctor Os. 2012: 789-796. Italian.

[9] Linkow LI. et al. United States Patent N. 3,729,825. Oral Implant. May $1,1973$.

https://patentimages.storage.googleapis.com/4a/cf/5e/3ef9954433ed7 6/US3729825.pdf

[10] Linkow LI. Performing 4 surgical procedures in front of the audience. Chicago Dental Society 1973 Midwinter Meeting.

[11] Linkow LI. The blade vent - a new dimension in endosseous implantology. Dent Concepts. 1968; 11(2): 3-12.

[12] Linkow L. Endosseous bladevent implant - insertion guidelines. Dent Today. 1984; 3.

[13] Linkow LI. Implant dentistry today. A multidisciplinary approach. Piccin Nuova Libraria Padova 1990.

[14] Linkow LI, Donath K, Lemons JE. Retrieval analyses of a blade implant after 231 months of clinical function. Implant Dent. 1992; 1(1): 37-43.

[15] Di Stefano D, Iezzi G, Scarano A, Perrotti V, Piattelli A. Immediately loaded blade implant retrieved from a man after a 20 -year loading period: a histologic and histomorphometric case report. J Oral Implantol. 2006; 32: 171-6.

[16] Trisi P, Quaranta M, Emanuelli M, Piattelli A. A light microscopy, scanning electron microscopy, and laser scanning microscopy analysis of retrieved blade implants after 7 to 20 years of clinical function. A report of 3 cases. J Periodontol. 1993; 64(5): 374-8.

[17] Meidan Z, Weisman S, Baron J, Binderman I: Technetium 99m-MDP scintigraphy of patients undergoing implant prosthetic procedures: a follow-up study. J. Periodontol. 1994; 65(4): 330-5.

[18] Dal Carlo L: Study over 7000 endosseous implants inserted during 25 years in 3300 interventions. clinical results in different anatomical and functional situations. statistical data and over 20 years iconographic documentation. Journal of Dental and Oral Health 2016; 2(6): 1-10.

[19] Linkow, LI, Winkler, S, Shulman, M, Dal Carlo L, Pasqualini ME, Rossi F, et al. A new look at the blade implant. The Journal of Oral Implantology. 2016; 42(4): 373-380.

[20] Dal Carlo L, Winkler S., Shulman M, Pasqualini ME, Rossi F, Mondani PM. Maxillary Arch Rehabilitation: A Case Report. J Oral Implantol. 2021; 47(4): 352-356.

[21] Strecha J, Jurkovic R, Siebert T, Prachar P, Bartakova S. Fixed bicortical screw and blade implants as a non-standard solution to an edentulous (toothless) mandible. Int J Oral Sci. 2010; 2(2): 105-10.

[22] Viscido AJ. Submerged functional predictive endosteal blade implants. Oral Implantol. 1974; 5: 195-209.

[23] Dental Tribune International. FDA considers reclassification of dental implants. News Americas [Internet] [cited on 2013 February 5]

[24] Iezzi G, Scarano A, Perrotti V, Tripodi D, Piattelli A. Immediately loaded blade implants. a histological and histomorphometrical evaluation after a long loading period. A retrospective 20 years analysis (1989-2009). J Osseointegr. 2012; 3(4): 39-42.

[25] Dal Carlo L, Linkow LI, Pasqualini ME, Shulman M, Grivet Brancot $\mathrm{L}$, et al. Blade implants in the rehabilitation of severely atrophic ridges. Annals of Oral \& Maxillofacial Surgery. 2013; 1(4): 33.

[26] Mangano F, Bazzoli M, Tettamanti L, Farronato D, Maineri M, Macchi A, et al. Custom-made, selective laser sintering (SLS) blade implants as a non-conventional solution for the prosthetic rehabilitation of extremely atrophied posterior mandible. Lasers Med-Sci. 2012; 28(5): 1241-1247.

[27] Diotallevi P, Dal Carlo L, Pasqualini ME, Mazziotti S, Nardone M, Moglioni E. Radiological evalutation of long term complications of oral rehabilitations of thin ridges with titanium blade implants. Journal of Osseointegration. 2014; 6(1).

[28] Bianchi AE, Gallini G, Fassina R, Sanfilippo F: Sem Analysis of BoneTitanium Interface of a Blade-Vent Implant. Il Dentista Moderno. 1994; 7: 1107-1113.

[29] Dal Carlo L. A new technique for inserting blade implants: endosseous distal extension. Dental cadmos. 2001; 69(16): 41-50.

[30] Strietzel FP, Krueger H, Semmler R, Hopp M. Morphological study of Osteoplate 2000 - extension implants after bending. Implant Dent. 2000; 9(3): 261-7.

[31] Cranin AN, Rabkin MF, Garfinkel L. Statistical evaluation of 952 endosseous implants. Riv Ital Stomatol. 1978; 47(1): 53-61.

[32] Proussaefs P, Lozada J. Evaluation of two vitallium blade-form implants retrieved after 13 to 21 years of function: a clinical report. $J$ Prosthet Dent. 2002; 87(4): 412-5.

[33] Dal Carlo L, Pasqualini M, Shulman M, Rossi F, Comola G, Manenti $\mathrm{P}$, et al. Endosseous distal extension (EDE) blade implant technique useful to provide stable pillars in the ipotrophic lower posterior sector: 22 years statistical survey. Int J Immunopathol Pharmacol. 2019; 33: $1-5$.

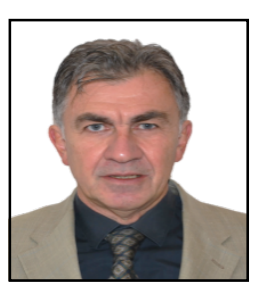

L. Dal Carlo was born in Venice, Italy, on October the $16^{\text {th }}, 1962$. He was graduated in Odontology and Prosthetic Dentistry at the Padua University on March $29^{\text {th }}, 1988$. Since that time, he holds a private practice in center Venice, Italy. Over 30 years experienced in multi-modal implant dentistry, intraoral welding, immediate loading and related prosthetics.

He is:

- the author of numerous courses and lectures about implant and prosthetic dentistry;

- lecturer for 5 consecutive years at the annual meeting of the "Odontology Professors Board" in Rome, Italy;

- one of the authors of the Odontology Dentistry Recommendations of the Italian Ministry of Health, 2014 and 2017 editions.

- author of 100 scientific articles about the topic of implant dentistry, whose contents have been incorporated in his text book "Elementi di Selezione degli Impianti Endoossei" 2020, Edizioni Accademiche Italiane. Several textbooks from Specialists of Implant Dentistry host chapters from him. - author of a 25 years statistical study over 7000 implants, with 5, 8, 10 years gate controls.

- president of the New Italian Implants Study Group (NuovoGISI) since 2009 .

- master of the American Academy of Implant Prosthodontics (AAIP). Active Member of the Societad Espanola de Implantes (SEI).

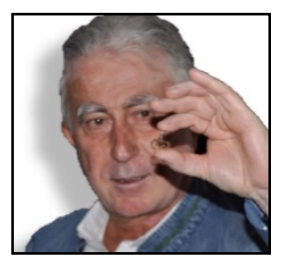

M. E. Pasqualini was born in Modena, Italy, on March 17th, 1952

He attended the University of Milan, graduating with a degree in medicine, and then earned a postgraduate degree cum laude in dentistry at the University of Modena, Italy. He was non-tenured professor of clinical maxillofacial prosthetics at the School of Dentistry, which is part of the Department of Medicine at the University of Modena (academic year 1991-92).

He held a non-tenured position with the Department of Medicine at the University of Bari, Italy, teaching "The role of plate-form implants in oral rehabilitation" as part of the coursework on oral diseases for the undergraduate program in dental hygiene (academic year 2001-02).

He was also a non-tenured professor at the Department of Dental Sciences of the School of Medicine at the Gabriele d'Annunzio University of Chieti for the postgraduate course on clinical implantology and biomaterials (academic year 2004-05) and the theoretical-practical refresher course on electrowelded implantology (academic year 200506), both of which directed by Stefano Fanali, professor of dentistry).

Author and co-author of 84 articles that have been published in national and international scientific journals, he has a personal photographic archive about dentistry composed of more than 20,000 slides. He worked with his uncle, Prof. Ugo Pasqualini, for 20 years in both daily practice and research work, and shares his scientific principles, outlined in the book "Occlusal pathologies. Pathogenesis and therapy" (Italian). 
He was vice president of A.I.S.I. (Italian Academy of Implant Stomatology), and he is a GISI (Italian Implant Study Group) fellow and a charter member of COM (Cenacolo Odontostomatologico Milanese). He was member of the board of directors of GISIGM (Giordano Muratori Italian Implant Study Group), directed by Prof. Francesco Mangini of the University of Bari.

He has been president of the SOMECOI (Società Medico Chirurgica di Odontoiatria Implantoprotesica) since 1999 and is a charter member of AIIP (Academia Internacional de Implantologia y Periodoncia). He is Master AAIP (American Accademy of Implant Prosthodontics) and active member of ICOI (International Congress of Oral Implantologists) and SEI (Sociedad Española de Implantes).

Author of the "Treatise Of Implant Dentistry, The Italian Tribute to the Modern Implantology" (2009) (PubMed indexed). As national and international lecturer, he has taught postgraduate courses for updates on implantology and occlusion. Dr. Pasqualini has a private practice in Milan, Italy.

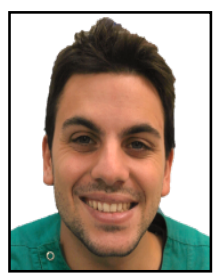

Z. Dal Carlo was born in Venice, Italy, on February the $27^{\text {th }}, 1996$. Degree in Odontology and Prosthetic Dentistry at the International University of Catalunya, Barcelona, Spain.

Member Nuovo GISI. Co-Author of the Implant textbook entitled "Elementi di selezione degli Impianti Endoossei”, EAI Berlin 2020.

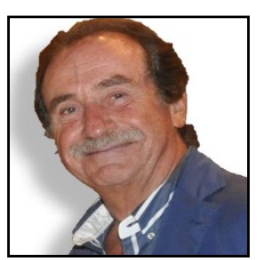

F. Rossi was born in Varese, Italy, on November the $9^{\text {th }}, 1944$. Occupational field: Doctor Surgeon Specialist in Dentistry. Professional Assignment 2013:

Professor in the master's degree in Implantology and Dentures Medical School University Catholic "Nostra Signora del Buon Consiglio" - Tirana, Albania.

Education and Training:

- 1971 Degree in Medicine and Surgery University of Milano;

- 1974 Specialized in anaesthesia and resuscitation University of Milano;

- 1978 Specialized in Dentistry University of Modena;

- 2009 Contributor to the book "Treatise of Implant Dentistry" of Ugo and Marco E. Pasqualini - Ariesdue Edition;

- 2009 Contributor to the book "Implantoprosthetic Atlas" of Pier Luigi Floris - Cic International Edition;

Further Informations:

- National Deputy Vice President and President of the Scientific Commission AISI (Italian Academy Stomatology Implantoprosthetic);

- Fellow AAIP (American Academy of Implant Prosthodontics);

- Fellow NuovoGISI (New Italian Group Implant Studies);

- Fellow SISOS (Italian Society of Odontostomathologic History);

- Fellow SEI (Societad Espanola De Implantes);

- National and international lecturer;

- Author of 76 scientific publications on national and international journals.

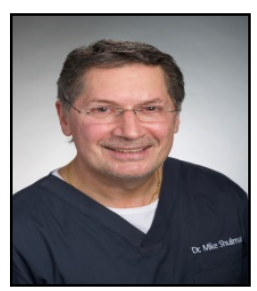

M. Shulman received his DDS from New York University College of Dentistry in 1993.

He graduated from the Latvia Medical Academy,

Riga, Latvia, in 1985 and completed his postgraduate training in oral surgery the following year at the Latvia Medical Academy.

$\mathrm{He}$ is certified to practice dentistry in all members of the European Union.

Dr. Shulman lectured nationally and internationally on oral implantology and presented many implant continuing education courses worldwide. He is founder and CEO of ADIS, Atlantic Dental Implant Seminars.

Dr. Shulman is former Adjunct Associate Professor of the School of Dental Sciences, University of Technology, Jamaica. He's a Master of the American Academy of Implant Prosthodontics. He is a Vice President of the American Academy of Implant Prosthodontics AAIP. He maintains private practices in New Jersey, USA. 